\title{
Ethiodized Oil
}

National Cancer Institute

\section{Source}

National Cancer Institute. Ethiodized Oil. NCI Thesaurus. Code C487.

A synthetic iodine addition product of the ethyl ester of the fatty acids of poppy seed oil. Ethiodized oil contains 37\% organically bound iodine and is used as a diagnostic radiopaque medium or, labeled with $\mathrm{I}-131$, as an antineoplastic agent. Selectively retained in tumor vessels for long periods, ethiodized oil is used for imaging organs such as liver, lung, stomach, and thyroid. Labeled with I-131 or other beta emitters (Y-90 or P-32), ethiodol can deliver a high internal radiation dose to certain tumors with minimal effect on healthy tissues. 